$\Phi=$

\title{
Variation in body mass index and their determinants among married women in Uttar Pradesh
}

\author{
Sonam Maheshwari ${ }^{1 *}$, Brijesh P. Singh ${ }^{2}$, O.P. Singh ${ }^{3}$, Puneet Kumar Gupta ${ }^{4}$ \\ ${ }^{I}$ Department of Community Medicine, SRMS-IMS, Bareilly-243202 \\ ${ }^{2}$ Faculty of Commerce \& DST-CIMS, Banaras Hindu University, Varanasi \\ ${ }^{3}$ Department of Kayachikitsa, Institute of Medical Science, Banaras Hindu University, Varanasi \\ ${ }^{4}$ Economics and Statistics Office, Vikas Bhawan, Rampur-244901 \\ *Corresponding author E-mail:maheshwarisonam2@gmail.com
}

\begin{abstract}
The body mass index of married women is a high quality sign of a country's health status as well as economic condition. Nutrition research in India has previously focused on the serious problem of under nutrition related to nutrient deficit and high rates of infection. BMI provide an indicator for supporting to wipe out many preventable diseases. Alteration in nutritional status plays an important role in the course of a person's health. Hence, BMI can be used as an indicator for nutrition status, and association with some diseases can be expected. This study observes the emerging nutrition transition among 7559 married and currently non -pregnant women aged between 15-49 years and also the differential impact of some demographic, socioeconomic, environmental and health-related factors on the body mass index living in Uttar Pradesh, India. The third wave of National Family Health Survey (2005-06) data provides nationally representative data on women's weight and height. Average BMI is $21.11 \mathrm{~kg} / \mathrm{m} 2$, and a turn down tendency in BMI was found during the last about 20 years. Body mass index increased with increasing age, education level of the woman, standard of living index. Lower BMI was especially pronounced among women who were living in rural areas, Hindus, employed women and women who are anemic.
\end{abstract}

Keywords:Anemia; NFHS-3; Logistics Regression.

\section{Introduction}

Nutrition research in India has focused primarily on the problem of under nutrition, particularly among vulnerable women and children. There is some evidence of an emerging nutrition transition in India. Data from other developing countries demonstrate that in many resource-poor settings, rising urbanization and improvements in economic development lead to concurrent under- and over nutrition in the population. Apart from these many socioeconomic factors play an important role on body weight as well as on height (but for a certain period of life). It is commonly assumed that economic factors have an indirect impact on body height and other anthropometric traits, and that these are indicators of living conditions and lifestyle. Well-nourished children from families with good socioeconomic conditions experience the growth spurt earlier than malnourished children from families with poor living conditions (Steckel, 1986; Bogin, 1999). A high correlation between anthropometric traits and parents' earnings, education, family size, residence, dietary habits and physical exercise has been reported (Bielicki, 1998). Unhealthy living conditions and malnutrition increase the risk of diseases, and frequent or untreated infections delay biological development (Bogin, 1999). BMI is defined as the weight in kilograms divided by the square of height in meters (kg/m2) (Mathus-Vliegen, 1998a; WHO, 2000). People with a BMI less than 18.50 are considered underweight. A BMI between 18.50 and 24.99 is a recommended range, and is considered as normal weight. People with a BMI equal to or exceeding 25.00 are considered overweight. BMI is positive correlated with both energy intake and physical activity. A small positive energy balance over longer periods of time leads to large body weight increase. This means that with respect to energy use, overweight could easily be caused by a relatively small but prolonged surplus in energy intake (Mathus-Vliegen, 1998; Cutler et al., 2003; Health Council of the Netherlands, 2003).

The human pattern of growth and development is unique, and different from the animal pattern. There are two intensive growth periods: the first three years of life and the growth spurt during adolescence, growth rate is much slower in other periods (Bogin, 1999). A number of genetic and environmental factors governed the Patterns of height growth from infancy to early adulthood but patterns of weight specially for women in India is mainly influenced by gender discrimination from birth, inequitable distribution of health resources and early and frequent reproductive cycling and infection. By nearly any measure, India remains one of the poorest countries in the world, with a population of over one billion and a fertility rate well above replacement level. It was observed in previous research improvements in the nutritional status of the population have been less impressive. More than half of the world's undernourished populations live in India. And more than half of Indian children are undernourished. More than half of Indian women are anemic; although the growing prevalence of overweight and obesity has received attention in many states.

More than one-third (36 percent) of women age 15-49 in India have a BMI below 18.5 indicating chronic nutritional deficiency, including 16 percent who are moderately to severely thin. The proportion of ever-married women who are thin (33 percent) has 
decreased slightly from 36 percent in NFHS-2. Women who are undernourished themselves are also much more likely than other women to have children who are undernourished. Obesity, the other side of poor nutrition, is a substantial problem among several groups of women in India, particularly urban women, welleducated women, women from households with a high standard of living, and among Non-Hindus. Fifteen percent of ever-married women are overweight or obese, up from 11 percent in NFHS-2. The aim of the present work was to test for the presence of trends in BMI of married, non-pregnant women born over three decades and to establish whether location of residence, demographic variables, diet, cultural, health and socioeconomic variables has an impact body mass index of women residing in Uttar Pradesh using third round NFHS dataset.

\section{Data and methods}

Cross-sectional data were derived from the National Family Health Survey (NFHS) conducted in 2005-06. The survey collected socio-demographic, health and lifestyle information from each subject. In addition, body height and weight were measured by those eight health coordinators, who had some medical background, were employed by IIPS for the supervision of data collection for biomarkers. Data from a sample of 12,183 women were collected by the 2005-06 NFHS. After removing outliers, cases with incomplete data, and excluding currently pregnant women, the data set was reduced to 7559 for the analysis in the present study. Variables tested for significance in their relation with BMI with the help of logistic regression. Two models were building up, model 1 introduces unadjusted ratio and model 2 introduce adjusted ratio.

In table 2, two logistic regression models were used to model the overweight vs. normal weight outcome for all women who were classified as overweight (BMI $\geq 25 \mathrm{~kg} / \mathrm{m} 2$ ) or normal weight (BMI $18.50-24.99 \mathrm{~kg} / \mathrm{m} 2$ ). A further two models for estimating underweight vs. normal weight were completed, with women classified as underweight $(\mathrm{BMI} \leq 18.50 \mathrm{~kg} / \mathrm{m} 2)$ or normal weight (BMI $18.50-24.99 \mathrm{~kg} / \mathrm{m} 2$ ). The analysis used 4722 and 5550 women for overweight vs. normal weight outcome and for underweight vs. normal weight outcome respectively. All statistical analyses were performed using SPSS (version 17.0).

\section{Result and discussion}

The mean BMI values of the study population are depicted graphically in Fig. 1 by birth year cohort from 1956 to 1990 . Yearly fluctuations in BMI are observed, and this is a characteristic of such cohort studies. There was an increasing trend during the first sixteen years from 1956 to 1971, but a decreasing trend thereafter. Consequently, a linear regression was found to be a good fit and the model explained $91.10 \%$ of the variation of the data (Fig. 1).

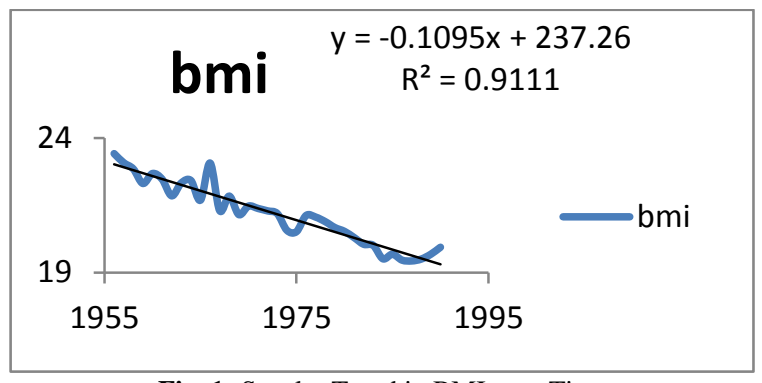

Fig. 1: Secular Trend in BMI over Time.

In Table 1, more than half of the participants in the current study were normal in weight $(53.6 \%)$, and $29.8 \%$ were underweight. Some participants were overweight $(16.6 \%)$. The results of the logistic regression analysis in which the outcome compares overweight women (BMI > $24.99 \mathrm{~kg} / \mathrm{m} 2)$ with those of normal weight (BMI 18.50-24.99 kg/m2) and the results of the logistic regression analysis in which the outcome compares underweight women (BMI $<18.50 \mathrm{~kg} / \mathrm{m} 2$ ) with those of normal weight (BMI 18.50$24.99 \mathrm{~kg} / \mathrm{m} 2$ ) are presented in Table 2 and Table 3 respectively. Results are presented as odds ratios with $95 \%$ confidence Intervals and p-values. In table 2, Regional variables account for many differences including market access, population density and climate. These variables can also capture dietary habits or practices, dietary references, price of meals, and opportunity cost of time or other preferences that are specific to some areas. These are main reasons behind the variation in probability of being overweight. Rural women have least likely chance of being overweight; as per model 1 in table 2 women residing in town have about two times more likely while women residing in small city four times more likely chance of being overweight in comparison to women residing in rural area.

Table 1:Frequency Distribution of BMI Categories of Married Women (N=7559)

\begin{tabular}{|c|c|c|}
\hline BMI category & $\mathrm{N}$ & Percentage \\
\hline Underweight (BMI $\leq 18.50 \mathrm{Kg} / \mathrm{m} 2)$ & 2251 & 29.8 \\
\hline Normal weight $(18.50<\mathrm{BMI} \leq 24.99 \mathrm{Kg} / \mathrm{m} 2)$ & 4052 & 53.6 \\
\hline Obese $($ BMI $>24.99 \mathrm{Kg} / \mathrm{m} 2)$ & 1256 & 16.6 \\
\hline
\end{tabular}

Table 2:Determinants of Obese Body Mass Index (BMI) > 24.99 Kg/M2 vs. Normal Weight (BMI 18.50-24.99 Kg/M2) Among Married Women inUP, India: Odds Ratios (OR) from Logistic Regressions

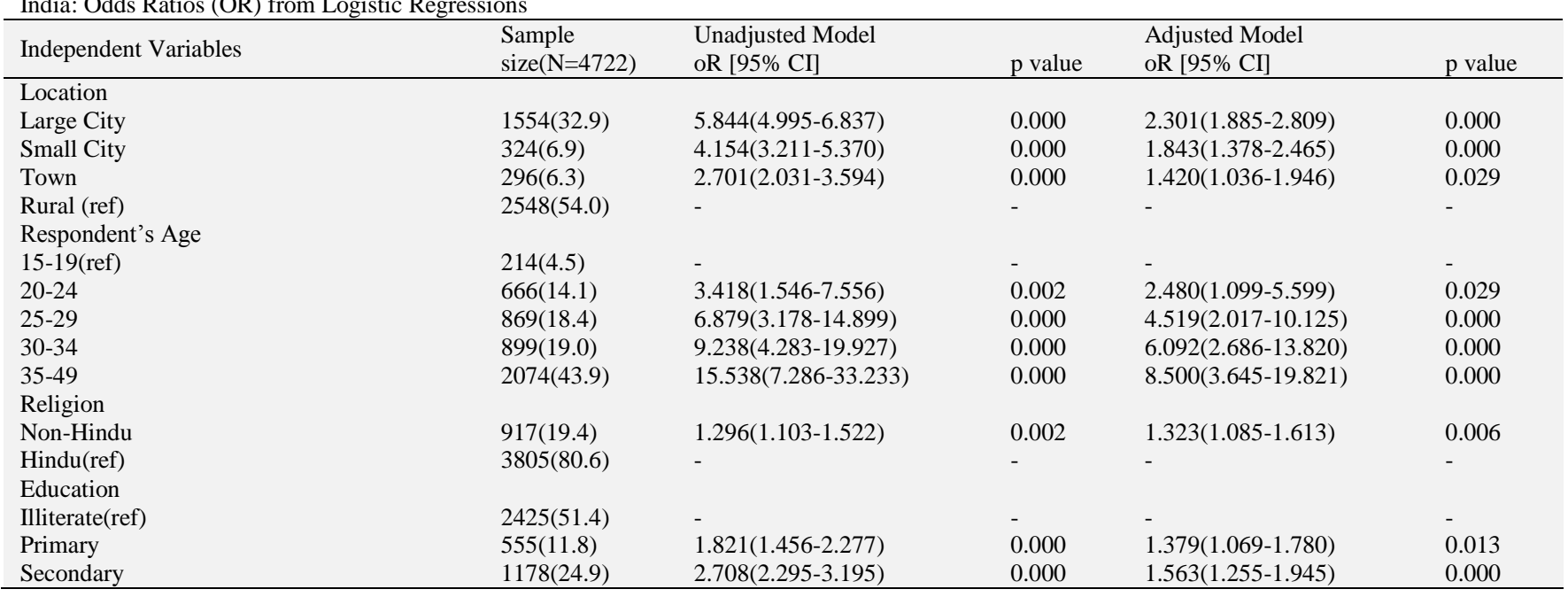




\begin{tabular}{|c|c|c|c|c|c|}
\hline Higher & $563(11.9)$ & $5.975(4.895-7.293)$ & 0.000 & $2.136(1.575-2.896)$ & 0.000 \\
\hline \multicolumn{6}{|l|}{ Standard of living index } \\
\hline Low(ref) & $705(14.9)$ & - & - & - & - \\
\hline Medium & $1448(30.7)$ & $1.814(1.282-2.567)$ & 0.001 & $1.046(0.989-1.786)$ & 0.003 \\
\hline High & $2569(50.4)$ & $9.098(6.637-12.472)$ & 0.000 & $7.856(2.345-10.536)$ & 0.000 \\
\hline \multicolumn{6}{|l|}{ Watches TV } \\
\hline Yes & $3169(67.1)$ & $3.966(3.317-4.742)$ & 0.000 & $1.283(1.022-1.609)$ & 0.031 \\
\hline No (ref) & $1553(32.9)$ & - & - & - & - \\
\hline \multicolumn{6}{|l|}{ Respondent's occupation } \\
\hline Not working & $3241(68.6)$ & $2.748(2.295-3.291)$ & 0.000 & $1.716(1.395-2.111)$ & 0.000 \\
\hline Physical Worker(ref) & $1301(27.6)$ & - & - & - & - \\
\hline \multicolumn{6}{|l|}{ Respondent eats fruit } \\
\hline Occasionally/rarely(ref) & $2998(63.5)$ & - & - & - & - \\
\hline Daily/weekly & $1724(36.5)$ & $1.359(1.314-3.412)$ & 0.000 & $1.218(1.027-1.444)$ & 0.023 \\
\hline \multicolumn{6}{|l|}{ Health Variables } \\
\hline Not Anemic & $2490(52.7)$ & $2.478(1.222-5.024)$ & 0.012 & $2.367(1.342-6.879)$ & 0.003 \\
\hline Mild Anemic & $1627(34.5)$ & $2.088(1.206-4.249)$ & 0.042 & $1.645(0.785-3.456)$ & 0.005 \\
\hline \multicolumn{6}{|l|}{ Demographic_Variables } \\
\hline Age at Marriage & $4722(100)$ & $1.160(1.135-1.185)$ & 0.000 & $1.091(0.987-2.456)$ & 0.000 \\
\hline \multicolumn{6}{|l|}{ Contraceptive use } \\
\hline Never_Used(ref) & $1998(42.3)$ & - & - & - & - \\
\hline Pill/IUD/Injection/modern Method & $912(19.3)$ & $2.108(1.765-2.517)$ & 0.000 & $1.567(1.456-3.659)$ & 0.000 \\
\hline Sterilized & $1131(24.0)$ & $1.800(1.519-2.132)$ & 0.000 & $1.213(1.009-2.348)$ & 0.000 \\
\hline Traditional Method & $681(14.4)$ & $1.213(0.981-1.500)$ & 0.075 & $1.122(0.896-2.344)$ & 0.067 \\
\hline
\end{tabular}

Ref- REFERENCE CATEGORY

Table 3:Determinants of Underweight Body Mass Index (BMI) < 18.50 Kg/M2 vs. Normal Weight (BMI 18.50-24.99 Kg/M2) Among Ever Married Women in UP, India: Odds Ratios (OR) From Logistic Regressions

\begin{tabular}{|c|c|c|c|c|c|}
\hline Independent Variables & $\begin{array}{l}\text { Sample size } \\
(\mathrm{N}=5550)\end{array}$ & $\begin{array}{l}\text { Unadjusted Model } \\
\text { OR }[95 \% \mathrm{CI}]\end{array}$ & $\mathrm{p}$ value & $\begin{array}{l}\text { Adjusted Model } \\
\text { OR }[95 \% \mathrm{CI}]\end{array}$ & $\mathrm{p}$ value \\
\hline \multicolumn{6}{|l|}{ Location } \\
\hline Rural & $3759(67.7)$ & $2.003(1.728-2.321)$ & 0.000 & $1.104(0.926-1.315)$ & 0.070 \\
\hline Town & $324(5.8)$ & $1.449(1.109-1.892)$ & 0.007 & $1.104(0.836-1.458)$ & 0.000 \\
\hline Small City & $297(5.4)$ & $1.255(0.946-1.663)$ & 0.115 & $1.134(0.848-1.517)$ & 0.487 \\
\hline Large City (ref) & $1170(21.1)$ & - & - & - & - \\
\hline \multicolumn{6}{|l|}{ Respondent's Age } \\
\hline $15-19$ & $335(6.0)$ & $1.190(0.938-1.511)$ & 0.152 & $1.113(0.860-1.439)$ & 0.416 \\
\hline $25-29$ & $1094(19.7)$ & $1.066(0.915-1.243)$ & 0.412 & $1.100(0.936-1.294)$ & 0.008 \\
\hline $30-34$ & 1098(19.8) & $1.165(1.001-1.357)$ & 0.049 & $1.153(0.984-1.352)$ & 0.007 \\
\hline 35-49 (ref) & $2065(37.2)$ & - & - & - & - \\
\hline \multicolumn{6}{|l|}{ Religion } \\
\hline Hindu & $4552(82.0)$ & $1.080(0.936-1.247)$ & 0.002 & $1.071(0.915-1.255)$ & 0.092 \\
\hline Non-Hindu(ref) & $998(18.0)$ & - & - & - & - \\
\hline \multicolumn{6}{|l|}{ Education } \\
\hline Illiterate & $3473(62.6)$ & $3.831(2.806-5.231)$ & 0.000 & $2.873(1.286-3.456)$ & 0.165 \\
\hline Secondary & $1131(20.4)$ & $2.353(1.692-3.272)$ & 0.000 & $1.597(0.675-1.992)$ & 0.005 \\
\hline Higher(ref) & $323(5.8)$ & - & - & & \\
\hline \multicolumn{6}{|l|}{ Standard of living index } \\
\hline Low & $1291(23.3)$ & $3.142(2.707-3.648)$ & 0.000 & $2.194(1.829-2.632)$ & 0.000 \\
\hline Medium & $2175(39.2)$ & $2.258(1.977-2.578)$ & 0.000 & $1.704(1.458-1.999$ & 0.000 \\
\hline High(ref) & $2084(37.5)$ & - & - & - & - \\
\hline \multicolumn{6}{|l|}{ Watches TV } \\
\hline Yes & $3053(55.0)$ & $0.515(0.461-0.575)$ & 0.000 & $0.777(0.680-0.887)$ & 0.000 \\
\hline No (ref) & 2497(45.0) & - & - & - & - \\
\hline \multicolumn{6}{|l|}{ Respondent's occupation } \\
\hline Not working & $3507(63.2)$ & $0.731(0.650-0.822)$ & 0.000 & $0.934(0.821-1.062)$ & 0.299 \\
\hline Service & $253(4.6)$ & $0.533(0.398-0.714)$ & 0.000 & $0.879(0.642-1.204)$ & 0.022 \\
\hline Physical Worker(ref) & $1790(32.3)$ & - & - & - & - \\
\hline \multicolumn{6}{|l|}{ Respondent eats fruit } \\
\hline Occasionally/rarely & $5300(95.5)$ & $2.899(2.071-4.058)$ & 0.000 & $1.629(1.141-2.326)$ & 0.007 \\
\hline Daily/weekly (ref) & $250(4.5)$ & - & - & - & - \\
\hline \multicolumn{6}{|l|}{ Health Variables } \\
\hline Not Anemic (ref) & $2731(49.2)$ & - & - & - & - \\
\hline \multicolumn{6}{|l|}{ Demographic_Variables } \\
\hline Age at Marriage & $5550(100)$ & $0.924(0.905-0.944)$ & 0.000 & $0.996(0.972-1.021)$ & 0.007 \\
\hline \multicolumn{6}{|l|}{ Contraceptive use } \\
\hline Never_Used (ref) & $2680(48.3)$ & - & - & - & - \\
\hline Pill/IUD/Injection/modern Method & $855(15.4)$ & $0.591(0.500-0.699)$ & 0.000 & $0.922(0.765-1.109)$ & 0.008 \\
\hline Sterilized & $1168(21.0)$ & $0.718(0.621-0.830)$ & 0.000 & $0.848(0.723-0.995)$ & 0.004 \\
\hline Traditional Method & $847(15.3)$ & $0.944(0.805-1.106)$ & 0.475 & $1.014(0.859-1.197)$ & 0.868 \\
\hline
\end{tabular}

Ref- REFERENCE CATEGORY 
Larger city women residents have most chance of being overweight among all women. Probability of being overweight is increasing with increment in age. Religion plays an important role in nutrition status of women because Non-Hindu women were more likely to be overweight than Hindu women. It is commonly assumed that socioeconomic and environmental factors have an indirect impact on overweight and that these are indicators of living conditions and lifestyle. Women who reported eating fruits daily or weekly were 35 percent more likely to be overweight or obese than those who ate them occasionally or rarely. The main reason behind this dietary variable is economic variable women who are well economic settled can easily purchase fruits. TV may also contribute to have about four times more probability of being overweight through the consumption of snack food lack of physical activity while watching TV. According to model 2, Women who did not work were significantly more likely to be overweight or obese than their counterparts who were working outside of the home. However, women in service have five times more probability of becoming overweight or obese compared with physical worker while house wives have two times more chance.

The standard of living index is all associated with overweight. Respondents with higher living index are nine times likely to be overweight than those with low standard of living index. The education effect on BMI may be due to higher capability to obtain information about the consequences of behaviour regarding food intake and physical activity, or to more healthy lifestyles related with higher education. Age at marriage is also found to be significant variable for obesity. As well as age is increasing women are more prone to be obese as discussed earlier. In this study we also try to find the impact of haemoglobin in blood of women and their BMI, it is observed that not anemic women have higher BMI as compared to who are moderate or severe anemic. Also, mild anemic women are two times more chance to being overweight. Use of contraceptive is also a decisive variable for BMI. Modern method user women have higher chance of being overweight and sterilized women have 80 percent more chance of higher BMI. In table 3, output of comparison underweight women (BMI< $18.50 \mathrm{~kg} / \mathrm{m} 2$ ) with those of normal weight (BMI 18.50-24.99 $\mathrm{kg} / \mathrm{m} 2$ ) with the help of logistic regression model is shown. The outputs are analogous to the output shown for the models of obesity and overweight. Rural women are about two times more likely to be underweight, similarly women residing in town and small city forty four and twenty five percent more likely to be underweight as compared to large city women. The main factors behind the impact of location variable take away from education, awareness for health life style and diet; the dietary variables significantly associated with being underweight were the reported frequency of consumption of fruits. Younger age was the most important demographic predictor of underweight. Socioeconomic and living environment variables associated with being underweight were also consistent with factors that predicted overweight and obesity status. Respondents belongs to low standard living index are much more likely to be underweight than those belong to higher socioeconomic status. Respondent's education was again a significant variable in models of underweight in model 2.

\section{Conclusion}

Looking at the whole sample population, it was noted that BMI is higher with increasing age, education level of women, standard of living index, exposure to mass media like TV and women who are taking fruits. Education can play an important role in improving women's knowledge of general health and balanced nutrition, and this is supported by the observed positive association between BMI and level of education. The majority of the study women were living in rural areas. Thus, people living in rural environments still face major health problems. The percentage of underweight women was higher in rural compared with urban regions, while the reverse was observed for the percentage of obese women.
Nowadays some wealthy adult women in India are very conscious of their body weight and try to keep themselves slim without performing any exercise and only controlling their diet. Consequently, they are not aware of the long-term medical problems related to being underweight. It may be necessary for the authorities to make the general population aware about the importance of a balanced diet and the need to make good conscious decisions on the health. Although the factors associated with underweight, obesity and overweight are very similar, the challenges and solutions required tackling the extremes of over- and underweight in the upper and lower socioeconomic groups are not. Educated people within high socioeconomic groups are the first to respond to nutrition education messages and reduce their risk of obesity MonteiroET. al (2001). Hence, providing health education messages and interventions for overweight women in the higher socioeconomic groups on healthy diets and healthy lifestyles might be effective in reducing the incidence of overweight and obesity in this group. However, for the lower socioeconomic groups, the challenges are far greater. Measham and Chatterjee suggest that one of the key causes of malnutrition among the poor in India is a lack of access to sufficient food and resource inequities. There is a need for continued commitment from the Indian government to ensure food security for the poor and for long-term rural development strategies. At the same time, information and programs for rural women are needed to help them to understand the components of a healthy diet and to ensure adequate access to health services.

\section{References}

[1] AlicjaKuskowska-Wolk, Bergstrom R (1993), Trends in body mass index and prevalence of obesity in Swedish men 1980-89", Journal of Epidemiology and Community Health, 47: 103108.http://dx.doi.org/10.1136/jech.47.2.103.

[2] Bielicki T (1998), Growth as an indicator of social inequalities, The Cambridge Encyclopedia of Human Growth and Development. S. Ulijaszek, F. E. Johnston and M. Preece eds. Cambridge: Cambridge University Press, pp: 54-56.

[3] Bogin, B. (1999), Patterns of Human Growth, Cambridge University Press, Cambridge.

[4] Cutler DM, Glaeser EL and Shapiro JM (2003), why have Americans become more obese? , Journal of Economic Perspectives, 17(3): 93118.http://dx.doi.org/10.1257/089533003769204371.

[5] International Institute for Population Sciences \& ORC Macro National Family Health Survey India 2005/06, IIPS, Mumbai, India.

[6] International Institute for Population Sciences (IIPS), World Health Organization (WHO), and World Health Organization (WHO) India WR Office. 2006. Health SystemPerformance Assessment: World Health Survey 2003 India. Mumbai: IIPS.

[7] Wronka I (2012), Body Height and Socioeconomic Status of Females at different life stages, J. of Biosocial Science, 1(1): 1-10.

[8] Mathus-Vliegen, EMH (1998a), Overweight I. Prevalence and trends (in Dutch), Ned TijdschrGeneeskd, 142(36): 1982-1989.

[9] Monteiro CA, Condey WL and Popkin BM (2001), Independent effects of income and education on the risk of obesity in the Brazilian adult population, J. Nutr. 131: 881S-886S

[10]Griffiths PL, Bentley ME(2001), the Nutrition Transition Is Underway in India, Community and International Nutrition, 131(10):2692-2700.

[11]Steckel RH (1986), a peculiar population: the nutrition, health, and mortality of American slaves from childhood to maturity, Journal of Economic History, 46:721-741 http://dx.doi.org/10.1017/S0022050700046842.

[12] Arnold BC (1993), Pareto Distributions. Vol.5 in statistical distribution, Fairland (MD), International Co-operative Publishing house. 